\title{
Human toxoplasmosis in Mozambique: gaps in knowledge and research opportunities
}

\author{
Leonardo Manuel' ${ }^{1}$ Gabriela Santos-Gomes ${ }^{2}$ and Emilia V. Noormahomed ${ }^{3,4,5 *}$
}

\begin{abstract}
Toxoplasmosis is a parasitic zoonotic disease caused by Toxoplasma gondii that afflicts humans worldwide and wild and domestic warm-blooded animals. In immunocompetent individuals, the acute phase of infection presents transient low or mild symptoms that remain unnoticed. In immunocompromised patients, T. gondii is a life-threatening opportunistic infection, which can result from the reactivation of latent infection or primary infection. Moreover, congenital toxoplasmosis, which results from the transplacental passage of tachyzoites into the fetus during a pregnant primary infection, can lead to miscarriage, stillbirth, or ocular and neurologic disease, and neurocognitive deficits in the newborns. Thus, the present review aims to address the current knowledge of T. gondii infection and toxoplasmosis in Africa and especially in Mozambique, stressing the importance of identifying risk factors and promote awareness among the health care providers and population, assessing the gaps in knowledge and define research priorities. In Mozambique, and in general in southern African countries, clinical disease and epidemiological data have not yet been entirely addressed in addition to the implications of T. gondii infection in immunocompetent individuals, in pregnant women, and its relation with neuropsychiatric disorders. The main gaps in knowledge in Mozambique include lack of awareness of the disease, lack of diagnostic methods in health facilities, lack of genetic data, and lack of control strategies.
\end{abstract}

Keywords: Toxoplasma gondii infection, HIV-infected patients, Congenital toxoplasmosis, Ocular toxoplasmosis, Mental disorders, South east African countries, Mozambique

\section{Background}

Toxoplasmosis is a zoonotic disease caused by the parasite Toxoplasma gondii, a cosmopolitan intracellular protozoan. This parasite can infect a wide range of warmblooded animals, including humans who act as intermediate hosts, supporting the asexual phase of the T. gondii life-cycle. Cats and wild felines have been considered definitive hosts since the sexual reproductive phase of the T. gondii life-cycle is restricted to these animals. People may become infected through the ingestion of raw or undercooked meat containing cyst, or by food and water contaminated with highly resistant and easily dispersed

*Correspondence: enoormahomed@gmail.com

${ }^{3}$ Department of Microbiology, Faculty of Medicine, Universidade Eduardo Mondlane (UEM), Maputo, Mozambique

Full list of author information is available at the end of the article
T. gondii oocysts from feline feces [1-3]. It seems that one to ten sporulated oocyst is enough to cause infection, giving rise to the asexual phase of the T. gondii lifecycle $[4,5]$. Infection also can be acquired by cysts after organ transplantation and by tachyzoites, which can cross the placenta during pregnancy, causing congenital toxoplasmosis and through blood transfusion [1, 2, 6]. Globally, it is anticipated that one-third of the world population is infected with $T$. gondii and that the prevalence of infection varies between $10-80 \%$, depending on local culture, eating habits, and climate [6-8]. In South America and tropical Africa, the prevalence of the disease is very high, with more than $50 \%$ of people infected, while in Europe, North America, and Southeast Asia the prevalence rates range from $7 \%$ to $50 \%[3,9,10]$. Studies conducted in several countries of Southeast Africa, 
such as Zambia, South Africa, Eswatini (former Swaziland), Zimbabwe, Angola, Namibia, Tanzania, Madagascar, Uganda, Kenya, Ethiopia, and Mozambique, indicate prevalence of $T$. gondii infection that ranges from $4 \%$ to 93\% in the general population [11-13]. Signs, symptoms, and the severity of $T$. gondii infection differs according to the immune status of the individual, the age in which the infection was acquired, and the genotype of the parasite involved [2, 3, 14-16]. In immunosuppressed patients due to human immunodeficiency virus (HIV) or immunosuppressive therapy, toxoplasmosis is considered a life-threatening parasitic disease. Despite the growing numbers of drug-immunosuppressed patients and the few available studies, these patients can also be at risk of developing toxoplasmosis, in particular, the transplanted patients $[17,18]$. Toxoplasma gondii genotyping studies recognize three major subtypes identified as subtype I, subtype II, and subtype III. Altogether they account for 95\% of isolates from North America and Europe, each leading to differences in disease severity $[2,3]$. In these regions, the majority of cases of congenital toxoplasmosis and toxoplasmosis infection in HIV immunosuppressed individuals are mainly caused by type II strains. However, most of the isolates from South America, Africa, and Asia do not fit into the three major lineages, except type III, which is really cosmopolitan and commonly found in animals $[2,19]$. Atypical, exotic, recombinant, or non-archetypal genotypes were found in other continents and the characterization of the strains by multilocus polymerase chain reaction-restriction fragment length polymorphism (PCR-RFLP), using ten genetic markers revealed 18 different genotypes. Together they account for $5 \%$ of infections, generating more virulent parasites due to its genetic diversity and the consequent increase of disease severity $[3,14,20]$. A large metaanalysis and a prospective cohort study showed a higher risk of ocular Toxoplasmosis in children from Brazil and Colombia than in European children (47\% versus 14\%). Furthermore, ocular lesions were large, numerous, and more likely to affect the retina that according to several authors may be explained by the predominance of atypical $T$. gondii strains in Latin America [21-23]. There are multiple tools available for the diagnosis of $T$. gondii infection, particularly serological, molecular, and imaging techniques. Serological assays allow the detection of T. gondii specific antibodies, immunoglobulin M (IgM) and immunoglobulin $\mathrm{G}$ (IgG). Usually, these tests possess high sensitivity and specificity due to antigen standardization and good assay reproducibility in immunocompetent individuals [24]. Molecular biological tests based on polymerase chain reaction (PCR) allow detection of parasite deoxyribonucleic acid (DNA) and identification of genetic variants, while imaging techniques, such as computed tomography and magnetic resonance imaging, that have been employed to evaluate expansive brain lesions of cerebral toxoplasmosis, present high sensitivity, but low specificity and should be used in combination with other diagnostic methodologies [2, 3, 25-27]. More recently, the use of recombinant antigens has been proposed as an alternative to conventional serological assays because of its limited value, especially in immunosuppressed patients $[3,28,29]$. Patients with confirmed toxoplasmosis have multiple treatment options, depending on immune competence and disease severity. However, most of the drugs used to treat toxoplasmosis are effective against tachyzoites, the acute morphological form of T. gondii, but do not seem to eradicate the encysted bradyzoites forms (chronic phase). Pyrimethamine combined with sulfadiazine and trimethoprim-sulfamethoxazole combined with spiramycin are the main choice for the clinical treatment of toxoplasmosis [30]. To prevent parasite transmission from a pregnant woman to her fetus spiramycin is the drug of choice. For congenital toxoplasmosis, pyrimethamine and sulfadoxine together with folinic acid to prevent bone marrow suppression are the recommended drugs to treat the newborn, while a combination of pyrimethamine, azithromycin, and corticosteroids is recommended for treating ocular toxoplasmosis [27]. Despite the limited reports available on the relative importance of toxoplasmosis in Africa and particularly in Mozambique, where the studies on human $T$. gondii infection are scarce, this review aims to: (i) summarize and critically examine the most relevant aspects of Toxoplasma infection and toxoplasmosis in Africa and, specifically in Mozambique; (ii) identify gaps of knowledge; (iii) highlight the research opportunities and reflect on its implications for the population well-being and for the socio-economic development of Mozambique.

\section{Toxoplasmosis in immunosuppressed patients}

In HIV-immunosuppressed patients and individuals undergoing cancer treatment or organ transplantation, Toxoplasma infection can become a severe opportunistic disease, which can result from a primary infection, but most of the time results from reactivation of an earlier acquired infection. Reactivation of bradyzoites (the dormant forms of this parasite) and differentiation in tachyzoites occurs as a consequence of patient's reduced immunocompetence, leading to tissue injury [31, 32]. In sub-Saharan Africa, where the majority (70\%) of HIV-infected people live [33], patients are commonly diagnosed with HIV after developing cerebral toxoplasmosis. It is estimate that this parasitic disease is indicative of HIV infection in 35\% of patients and an acquired immunodeficiency syndrome (AIDS) defining event in $75 \%$ of the cases $[3,32,34,35]$. With access to 
combination antiretroviral therapy (cART), the incidence of encephalitis caused by $T$. gondii in $\mathrm{HIV}^{+}$patients have reduced dramatically. Before the anti-retroviral treatment era, rates of cerebral toxoplasmosis in the USA and the UK ranged between 16 and 40\%, in Brazil 50 to $80 \%$, in France 75 to $90 \%$, and in Spain, it was about $60 \%$ [36]. In Ethiopia, a serological study in HIV-infected patients found Toxoplasma infections ranging from 3\% to $97 \%[37,38]$. In Uganda anti-T. gondii antibodies were detected in $54 \%$ of $\mathrm{HIV}^{+}$patients and $23 \%$ present parasites in the peripheral blood [39], pointing for an acute infection that possibly represents a reactivation. On the contrary, in Johannesburg (South Africa), the prevalence of latent Toxoplasma infection was lower in HIV infected patients, ranging between $8 \%$ and $18 \%[40,41]$. Moreover, in Nigeria, $85.5 \%$ of HIV/AIDS patients that were under cART present latent Toxoplasma infection (seropositive for $T$. gondii IgG) and almost 40\% (39.7\%) exhibited focal neurological signs [42]. Taken together, these findings indicate that in the African continent, there is a high variability $T$. gondii infection prevalence, which can go from residual values to very high levels. These differences can be associated with the socioeconomic conditions, including the efficacy of health systems and health education and population traditional culture, values, customs, and beliefs.

Although several studies argued for the role of genotypes in the clinical expression of human toxoplasmosis and the geographical structure of Toxoplasma across continents, genetic data concerning $T$. gondii isolates from Africa are scarce. In a study performed in $\mathrm{HIV}^{+}$ patients from Uganda, the genotype II $(12 / 22)$ was the most commonly found, followed by the type I genotype $(5 / 22)$. The less representative genotypes were non-III $(3 / 22)$ and type III $(2 / 22)$ [39].

\section{Toxoplasmosis in neonates and infants}

Women at risk of transmitting congenital toxoplasmosis include immunocompetent women when becoming newly infected during pregnancy or challenged with atypical parasite strains, as well as, immunosuppressed mothers with HIV/AIDS when the reactivation of bradyzoites occur during pregnancy [2, 15, 43]. Women that have acquired $T$. gondii infection before pregnancy have a limited risk of inducing a congenital infection. Primary infection during pregnancy does not cause specific symptoms, being unnoticed in most of the women, or lead to some transient low to mild symptoms that usually are not taken into consideration by the patient. In African countries, dating Toxoplasma infection during pregnancy is difficult, and the use of specific serology and the respective follow-up is often not extended to all pregnant women [44].
According to earlier studies in southern Africa, $T$. gondii seroprevalence among pregnant women ranges between 15 and 23\% [39, 45, 46] and HIV-Toxoplasma co-infection was about 8\% [47]. However, in sub-Saharan Africa, more recent studies among pregnant women pointing through $T$. gondii-seroprevalences ranging between $5.9 \%$ and $85.5 \%$. [48, 49]. As a consequence of the very high levels of $T$. gondii transmission among the Nigerian population (78\%), Toxoplasma infection during pregnancy was about $30 \%[50,51]$, representing a serious threat for congenital infection.

The risk factors for becoming infected have been identified. Eating raw meat, unwashed fresh vegetables or fruits, and undercooked food, drinking unpasteurized milk, and the proximity to cats seems to be predictors of possible infections [44]. Even so, the prevalence of Toxoplasma infection in pregnancy appears to be an underestimated public health concern in Africa, highlighting the urgent need for further research. Furthermore, the awareness of toxoplasmosis and its mode of transmission among women and, in particular, pregnant women seems to be limited [12, 52].

The risk of vertical transmission to the fetus, as a consequence of crossing the placental barrier by tachyzoites, increases during pregnancy, and about $60 \%$ to $81 \%$ of the infections by $T$. gondii occur during the last trimester $[2,53]$. However, the disease is more severe in the early stages of pregnancy, depending on parasite virulence and of the infected T. gondii genotype. In the first trimester, the rate of infection can range from $15 \%$ to $25 \%$ [10, 25, 54-57]. Congenital toxoplasmosis has been associated with a wide range of adverse outcomes, which includes spontaneous miscarriage, stillbirth, ocular disease, and neurologic and neurocognitive deficits. The most frequent presentation of congenital toxoplasmosis comprises of hydrocephalus, chorioretinitis, and cerebral calcifications. In up to $80 \%$ of cases, the infection remains asymptomatic after birth, but infants may later present mental retardation and learning and visual disabilities $[2,12,53]$. In upper-middle-income countries, the incidence of congenital hydrocephalus is at 0.5 cases per 1000 live births, whereas in Africa and Latin America the incidence of neonatal hydrocephalus was estimated to be around 145 and 316 per 100.000 births, respectively [58, 59]. In Nigeria it was determined that abortion occurred in $41.6 \%$ to $60 \%$ of pregnant women presenting anti-Toxoplasma antibodies, stillbirth happened in $6.8 \%$ to $61.5 \%$ of the cases, and neonatal death in $62.5 \%$. Ocular problems occurred in $29.4 \%$ of newborns [60-62]. Torgerson and Mastroiacovo [63] estimated per 1000 live births the incidence of congenital cases accounting for 2-2.4 to 13-15 of all Disability-Adjusted Life Years (DALYs) for the African continent, despite several African countries 
have not reported cases of congenital toxoplasmosis or seroprevalence data. Infants can also acquire primary Toxoplasma infection after birth and develop severe disease $[3,35,64]$.

In a recent study in Tunisia, $T$. gondii isolated from the amniotic fluid and placenta of women that had an acute infection during pregnancy was revealed to be of the type II genotype [65]. However, no other published studies on T. gondii genotypes occurring on the African continent were found, especially in sub-Saharan African countries.

\section{Toxoplasma infection in immunocompetent patients}

Studies conducted in immunocompetent individuals living in European countries or North America found that primarily acquired $T$. gondii infection is asymptomatic and self-limited in more than $80 \%$ of individuals $[3,66]$. In a few cases, patients may present fever or cervical lymphadenopathy, sometimes associated with myalgia, asthenia, or other non-specific clinical signs that can be misdiagnosed with different clinical conditions, exhibiting similar symptoms. The knowledge of the neuropathology caused by Toxoplasma is progressing. [3, 57, 67-69]. The immune response of chronically infected patients is mainly characterized by interferon $-\gamma$ production which induces the activation of indoleamine-2,3-dioxygenase leading to tryptophan (amino acid essential for serotonin biosynthesis) depletion, increase of kynurenic acid, and decrease of serotonin. Moreover, high tyrosine hydrolase activity directs dopamine release. Thus, high levels of kynurenic acid and dopamine, along with low amounts of serotonin are associated with cognitive dysfunctions [3].

Schizophrenia is a serious psychiatric disorder with a lifetime prevalence of approximately $1 \%$ and is rated as the 9th most common cause of disability all over the world [67]. Since 1953, more than 19 studies were done in patients with schizophrenia and other severe psychiatric disorders, testing for antibodies against $T$. gondii. Of these, 18 studies found patients with a higher frequency of anti-T. gondii antibodies, and in 11 out of 18 , the association was statistically significant [57]. These conditions are indicated as the leading cause of disability in the world, accounting for $22.7 \%$ of DALYs [69].

A systematic review on the relationship between Toxoplasma infection and epilepsy concluded that this parasitic infection should be an epilepsy risk factor and that there is a need to conduct more studies to determine the real impact of $T$. gondii infection on epilepsy [70, 71]. Moreover, studies conducted in Turkey and USA, in patients with cryptogenic epilepsy which aimed to evaluate its possible relationship with $T$. gondii found $54 \%$ and
$75 \%$ of these patients infected with Toxoplasma, respectively [72, 73].

In Southeast Africa, there is a scarcity of studies aiming to define the relationship between epilepsy and Toxoplasma infection. A multicenter study conducted in Kenya, South Africa, Uganda, Tanzania, and Ghana in a total of 1711 individuals with active convulsive epilepsy found an odds ratio of 1.39 with previous exposure to $T$. gondii [74]. Moreover, studies from Kenya and other African countries concluded that in addition to Toxoplasma infection, malaria, onchocerciasis, neurocysticercosis, and toxocariasis also might be involved in the pathogenesis of epilepsy $[75,76]$. There is also evidence of possible association with some neurodegenerative disorders, such as Parkinson and Alzheimer diseases, in which the prevalence of Toxoplasma infection is around $85 \%$ and $66 \%$, respectively [3, 77-81]. Suicidal behaviour is also a common problem in southeast Africa. A study from South Africa found that $3.2 \%$ of adolescents attempted to commit suicide, 5.8\% planned, and 7.2 reported ideation [82]. In Zambia, acute psychotic syndrome is the most common outpatient diagnosis, followed by schizophrenia, substance use disorder, and dementia [83]. Although $T$. gondii infection was considered a potential risk factor for suicide attempts [84], no studies exist reporting possible links between suicide attempts and Toxoplasma infection in Africa.

\section{Burden of pathological disorders related possibly to Toxoplasma infection in Mozambique}

Mozambique is a low-income country located in Southeast Africa, with 28.8 million people, a child mortality rate of $57.9 \%$, an adult literacy rate of $60.7 \%$, and with most of the population (about 66\%) living in rural areas [85]. According to the United Nations Development Programme [86], this country ranks 180th on the human development index, which points towards a high unmeet in health care performance, low education levels, and basic living standards [87]. The national health system covers only $50 \%$ of the population, and according to the Mozambique Poverty Reduction Action Plan 2011-2014 [88] $65 \%$ of the population have access to a health unit facility within 45 min walking distance of their homes. Despite natural fluctuations according to geographical settings, tuberculosis, HIV, malaria, neglected tropical diseases, in addition to respiratory and diarrheal diseases, still are significant causes of morbidity and mortality in Mozambique and among Southeastern African countries [87, 89-91] Furthermore, non-infectious diseases, including cardiovascular diseases, cancer, chronic respiratory diseases, and diabetes also accounts for disease burden in Mozambique [92]. 
In 2018, the prevalence of HIV in Mozambique was $12.6 \%$ in the age group of 15 to 49 years-old and 45,000 AIDS deaths [93], with nearly 2.2 million people living with HIV infection $[94,95]$. Together with some of the neighboring countries, such as Eswatini, South Africa, Zimbabwe, Zambia, Malawi, and Tanzania, Mozambique is among the top ten countries presenting the highest prevalence of HIV in the world, which ranges from $6.5 \%$ to $27.2 \%$ [91].

Toxoplasma gondii infection can also be related to mental disorders in immunocompetent individuals and in immunocompromised patients, in addition to the neurologic disorders of congenital toxoplasmosis. There was a significant improvement in the Mozambique mental health services, reaching rates of 0.59 mental health outpatient facilities and 0.09 psychiatric hospitals for 100,000 persons [96]. Mozambique has a suicide rate of 4.9 and a total of 1412 suicides per year, being in the 134 position in the global suicide rank [97]. However, this country has no published national suicide statistics. Even so, a crosssectional study performed in unnatural death, recorded from 2000-2009 at the Forensic Services in Maputo Central Hospital, reported 9\% of suicide [98]. Epilepsy affects 50 million people worldwide, and about $80 \%$ live in low-income countries [99]. According to a previous study, Mozambique has a prevalence of $1.6 \%$ for epilepsy, pointing out to more than 400,000 individuals living with epilepsy [100]. However, most of these patients seemed to be children and adolescents [101]. Hydrocephalus is a serious problem in sub-Saharan Africa and despite there is little information about this disorder, it was predicted that in Mozambique an incidence of 2900 to 4800 cases of neonatal hydrocephalus occur per year [102]. Despite the high rates of HIV infection in Southeast Africa, including Mozambique, the high incidence of hydrocephalus in sub-Saharan Africa and Mozambique, and the high prevalence of mental disorders, Toxoplasma infection still is overlooked in Mozambique. According to the International Agency for the Prevention of Blindness [103] in Mozambique, sight disease affects more than 300,000 persons from Maputo (capital of Mozambique) and Inhambane province, most of the cases are reported as cataract, glaucoma, and trachoma. Despite these numbers, there is no study or report about the incidence of ocular toxoplasmosis in Mozambique.

Though, little is known about the burden of toxoplasmosis in Southeastern Africa and Mozambique. In particular, the identification of risk factors, the genetic diversity of the parasite, as well as, Toxoplasma association with HIV, was not examined, the incidence of Toxoplasma infection in pregnant women, and the relationship with hydrocephalus and neuropsychiatric disorders, such as epilepsy, schizophrenia, suicidal behaviors, mood disorders, obsessive-compulsive disorder, and generalized anxiety [104] among other conditions, was not examined.

\section{Toxoplasma infection in Mozambique}

Although $T$. gondii is commonly associated with immunodeficiency disorders, a limited number of studies have been performed in Africa and, to the best of our knowledge, nobody has previously investigated the risk of reactivation of latent $T$. gondii infection in Mozambique $\mathrm{HIV}^{+}$patients, for example. However, in the last decade a cross-sectional study in $\mathrm{HIV}^{+} /$AIDS patients performed in Maputo (Mozambique) found a $46 \%$ prevalence of antiToxoplasma IgG, pointing towards a latent Toxoplasma infection among almost half of $\mathrm{HIV}^{+} /$AIDS patients. This study also identified the regular consumption of cattle meat, breeding cats and dogs, and regular contact with the soil as risk factors to acquire Toxoplasma infection [11]. Another study aiming to assess clinic-pathological discrepancies in the diagnosis of causes of death in HIV infected adults from Mozambique found that none of the $8 / 73(9.6 \%)$ cases of toxoplasmosis confirmed in the autopsy were clinically suspected, indicating $100 \%$ of major clinical discrepancies [105] (Fig. 1).

Congenital toxoplasmosis can cause miscarriage, blindness, deafness, hydrocephalus, and brain damage. Newborns may appear healthy at birth, but later in life can suffer from eye diseases, or have cognitive difficulties. Moreover, screening of Toxoplasma infection during pregnancy and specific treatment resulted in a decrease of $T$. gondii transmission from mother to child and a consequent reduction of clinical sequelae in infants [43]. There are no published data on the burden of congenital toxoplasmosis in Mozambique, nor its relation with hydrocephalus, seizures and mental retardation, which are disorders prevalent in Mozambique as already referred. A previous study performed by Sitoe et al. [106] in 150 pregnant women seeking the first trimester prenatal care in Maputo Central Hospital (Maputo, Mozambique) reported an overall prevalence of $18.7 \%$ of Toxoplasma IgG antibodies with the occurrence of $31.3 \%$ in $\mathrm{HIV}^{+}$pregnant women and $10.9 \%$ in immunocompetent pregnant women (Fig. 1). Taking into account the dimension of this study, the findings indicate the less than $25 \%$ of the pregnant woman had previous contact with T. gondii and that part of these women were Toxoplasma/HIV co-infected. In the same study, only one woman presenting significant levels of anti-Toxoplasma IgM was found [106], pointing towards a lower occurrence of active $T$. gondii infection during the first trimester of pregnancy in Maputo. The incidence of neonatal hydrocephalus in Mozambique was estimated to be 3-5 cases per 1000 live births [102], which leads to severe 


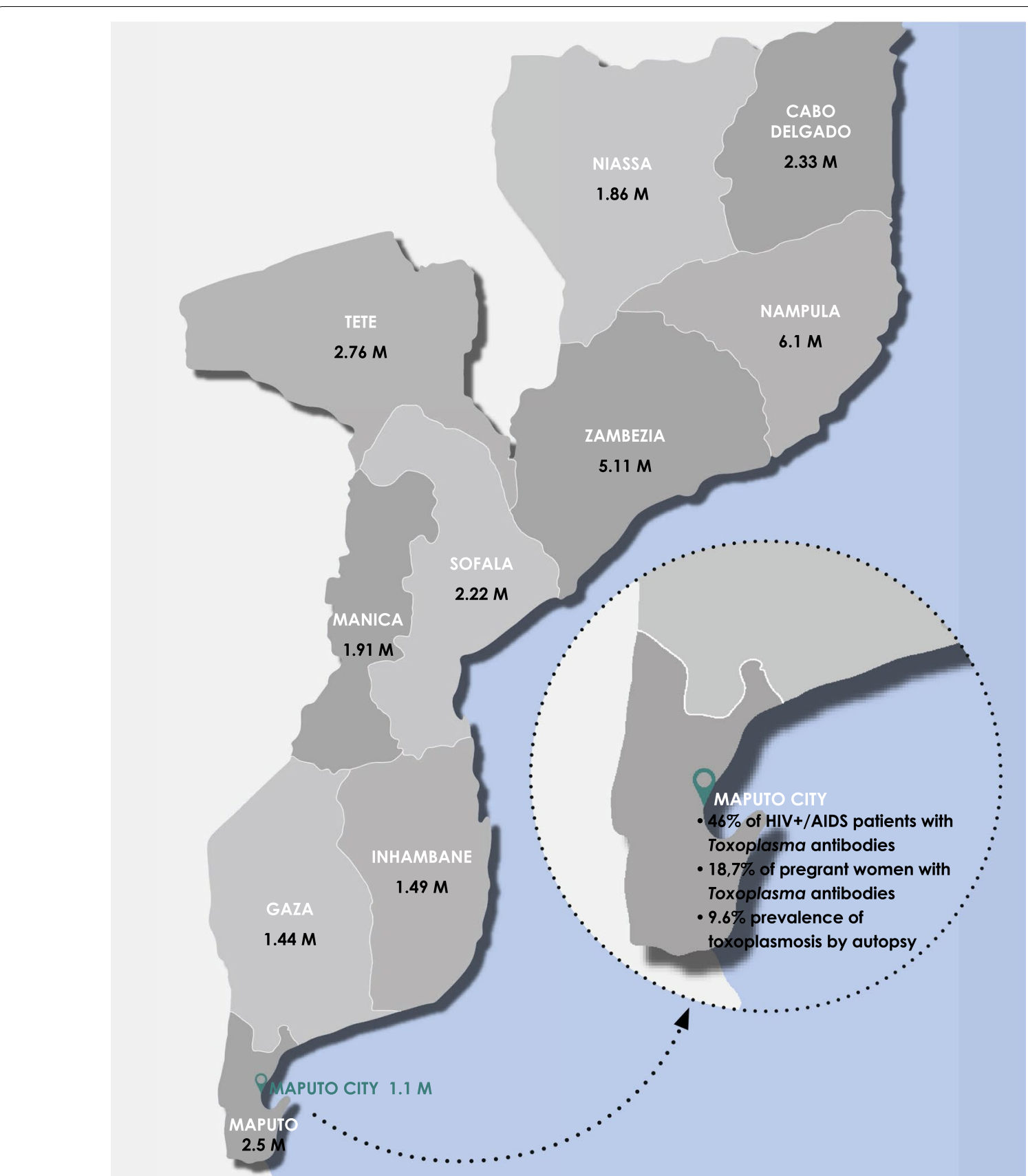

Fig. 1 Toxoplasma studies reported in Mozambique. Map indicating the population of each Mozambique province following the 2017 census [85], and where the published studies were made. Abbreviation: $\mathrm{M}$, millions

disability as is a significant cause of morbidity and mortality. However, the proportion of children that acquired $T$. gondii infection during pregnancy and developed congenital toxoplasmosis is not known. Similarly, there are no studies available on the importance of $T$. gondii infection in ocular disease, mental retardation, schizophrenia and epilepsy either in children or in adults living in Mozambique.
Moreover, in Mozambique, there are no available data on the clinical expression and severity of human toxoplasmosis in the diverse segments of the population and across the different regions, identification of $T$. gondii strains that circulate in the country, and on the dynamics of parasite transmission. 


\section{Conclusions}

Toxoplasma gondii is a globally widespread parasite that invades and chronically persists in the central nervous system of infected individuals. The complexity of this infection is a consequence of the intimate relationship established between the parasite and the host immunity, which can lead to persistent infections of limited pathogenesis. Further advances in the understanding of Toxoplasma infection have found a link between this parasite, mental and mood disorders, and suicidal behavior. However, this parasitic infection should not be evaluated from a restricted anthroponotic perspective since wild and domestic animals are involved in parasite genetic recombination and transmission. Moreover, molecular studies contributed to identifying different parasite strains associated with virulence levels and implicated in the specific clinical characteristics of the disease. Thus, it is of utmost importance to estimate the incidence of $T$. gondii infection and toxoplasmosis among the Mozambique population. The few available studies reflect the reality of Maputo, the Mozambique capital, and comprehensive information for the entire country is missing. Furthermore, understanding the extension of $T$. gondii infection and the risk factors associated is a pre-requisite for the development of effective control measures. Then, it is urgent to develop and implement research programs directed to the gaps of knowledge, which include up-todate information on T. gondii geographical distribution, the incidence and risk factors of immunocompetent, congenital, and perinatal infection, the occurrence of ocular toxoplasmosis, the association of Toxoplasma infection with mental and neurodegenerative disorders, as well as the identification of $T$. gondii genotypes circulating in Mozambique and its relation to morbidity and mortality. The research priorities identified for Mozambique can be an excellent starting point to inspire neighboring eastern African countries to foster research, in particular on this parasitic infection, and thus increasing knowledge in scientific and clinical areas, promoting the reduction of social impacts related to disability and consequent labor hours lost and advance the social-economic conditions.

\section{Abbreviations \\ AIDS: acquired immunodeficiency syndrome; DNA: deoxyribonucleic acid; HIV: human immunodeficiency virus; PCR-RFLP: polymerase chain reaction-restric- tion fragment length polymorphism; lgG: immunoglobulin G; IgM: immuno- globulin M; PCR: polymerase chain reaction; CART: combination antiretroviral therapy; DALYs: Disability-adjusted life years.}

\section{Acknowledgements}

The authors are grateful to Professor Virgilio do Rosário, retired Professor from Instituto de Higiene e Medicina Tropical, Universidade Nova de Lisboa, for his mentorship during the manuscript writing.

\section{Authors' contributions}

LM performed the literature review and was a major contributor in writing the manuscript, GG and EVN conceptualized, and revised the manuscript. All authors read and approved the final manuscript.

\section{Funding}

The research work and student fellowship were supported by the Grant D43TW010568-02, titled Enhanced Advanced Biomedical Research Training in Mozambique from the National Institutes of Health (NIH)- Fogarty International Center. The content is solely the responsibility of the authors and does not necessarily represent the official views of the Fogarty International Center or the National Institutes of Health.

Availability of data and materials

Not applicable.

\section{Ethics approval and consent to participate}

Not applicable.

\section{Consent for publication}

Not applicable.

\section{Competing interests}

The authors declare that they have no competing interests.

\section{Author details}

${ }^{1}$ Faculty of Health Sciences, Universidade Lurio, Nampula, Mozambique.

${ }^{2}$ Global Health and Tropical Medicine (GHTM), Instituto de Higiene e Medicina Tropical (IHMT), Universidade Nova de Lisboa (UNL), Lisbon, Portugal.

${ }^{3}$ Department of Microbiology, Faculty of Medicine, Universidade Eduardo Mondlane (UEM), Maputo, Mozambique. ${ }^{4}$ Department of Medicine, Infectious Disease Division, University of California, San Diego, USA. ${ }^{5}$ Mozambique Institute for Health Education and Research (MIHER), Maputo, Mozambique.

Received: 11 Auqust 2020 Accepted: 30 October 2020

Published online: 11 November 2020

References

1. Ajzenberg D, Lamaury I, Demar M, Vautrin C, Cabie A, Simon S, et al. Performance testing of PCR assay in blood samples for the diagnosis of toxoplasmic encephalitis in AIDS patients from the French departments of America and genetic diversity of Toxoplasma gondii: a prospective and multicentric study. PLoS Negl Trop Dis. 2016;10:e0004790.

2. Bruggmann D, Handl V, Klingelhofer D, Jaque J, Groneberg DA. Congenital toxoplasmosis: an in-depth density-equalizing mapping analysis to explore its global research architecture. Parasit Vectors. 2015;8:646.

3. Xiao J, Prandovszky E, Kannan G, Pletnikov MV, Dickerson F, Severance EG, et al. Toxoplasma gondii: biological parameters of the connection to schizophrenia. Schizophr Bull. 2018:44:983-92.

4. Dubey JP. Toxoplasma gondii infections in chickens (Gallus domesticus): prevalence, clinical disease, diagnosis and public health significance. Zoonoses Public Health. 2010;57:60-73.

5. Petersen E, Vesco G, Villari S, Buffolano W. What do we know about risk factors for infection in humans with Toxoplasma gondii and how can we prevent infections? Zoonoses Public Health. 2010;57:8-17.

6. Laboudi M. Review of toxoplasmosis in Morocco: seroprevalence and risk factors for Toxoplasma infection among pregnant women and HIVinfected patients. Pan Afr Med J. 2017;27:269.

7. Pan M, Lyu C, Zhao J, Shen B. Sixty years (1957-2017) of research on toxoplasmosis in China-an overview. Front Microbiol. 2017:8:1825.

8. Samojlowicz D, Twarowska-Malczynska J, Borowska-Solonynko A, Poniatowski LA, Sharma N, Olczak M. Presence of Toxoplasma gondii infection in brain as a potential cause of risky behavior: a report of 102 autopsy cases. Eur J Clin Microbiol Infect Dis. 2019;38:305-17.

9. Prusa AR, Kasper DC, Olischar M, Husslein P, Pollak A, Hayde M. Evaluation of serological prenatal screening to detect Toxoplasma gondii infections in Austria. Neonatology. 2013;103:27-34. 
10. Prusa AR, Kasper DC, Sawers L, Walter E, Hayde M, Stillwaggon E. Congenital toxoplasmosis in Austria: prenatal screening for prevention is cost-saving. PLoS Negl Trop Dis. 2017;11:e0005648.

11. Domingos A, Ito LS, Coelho E, Lucio JM, Matida LH, Ramos AN Jr. Seroprevalence of Toxoplasma gondii lgG antibody in HIV/AIDS-infected individuals in Maputo, Mozambique. Rev Saude Publica. 2013;47:890-6.

12. Onduru OG, Rumisha SF, Munyeme M, Phiri AM. Evaluation of the level of awareness of congenital toxoplasmosis and associated practices among pregnant women and health workers in Tanzania's Temeke district in Dar es Salaam. Afr Health Sci. 2019;19:3027-37.

13. Paul E, Kiwelu I, Mmbaga B, Nazareth R, Sabuni E, Maro A, et al. Toxoplasma gondii seroprevalence among pregnant women attending antenatal clinic in northern Tanzania. Trop Med Health. 2018;46:39.

14. Hosseini SA, Amouei A, Sharif M, Sarvi S, Galal L, Javidnia J, et al. Human toxoplasmosis: a systematic review for genetic diversity of Toxoplasma gondii in clinical samples. Epidemiol Infect. 2018;147:1-9.

15. Lindsay DS, Dubey JP. Toxoplasma gondii: the changing paradigm of congenital toxoplasmosis. Parasitology. 2011;138:1829-31.

16. Shimokawa PT, Targa LS, Yamamoto L, Rodrigues JC, Kanunfre KA, Okay TS. HLA-DQA1/B1 alleles as putative susceptibility markers in congenital toxoplasmosis. Virulence. 2016;7:456-64.

17. Dard C, Marty P, Brenier-Pinchart MP, Garnaud C, Fricker-Hidalgo H, Pelloux H, et al. Management of toxoplasmosis in transplant recipients: an update. Expert Rev Anti Infect Ther. 2018;16:44-760

18. Robert-Gangneux F, Meroni V, Dupont D, Botterel F, Garcia JMA, Brenier-Pinchart MP, et al. Toxoplasmosis in transplant recipients, Europe, 2010-2014. Emerg Infect Dis. 2018;24:1497-504.

19. Howe DK, Honore S, Derouin F, Sibley LD. Determination of genotypes of Toxoplasma gondii strains isolated from patients with toxoplasmosis. J Clin Microbiol. 1997;35:1411-4.

20. Switaj K, Master A, Borkowski PK, Skrzypczak M, Wojciechowicz J, Zaborowski P. Association of ocular toxoplasmosis with type I Toxoplasma gondii strains: direct genotyping from peripheral blood samples. J Clin Microbiol. 2006;44:4262-4.

21. Vasconcelos-Santos DV, Machado Azevedo DO, Campos WR, Orefice F, Queiroz-Andrade GM, Carellos EV, et al. Congenital toxoplasmosis in southeastern Brazil: results of early ophthalmologic examination of a large cohort of neonates. Ophthalmology. 2009;116(2199-205):e1.

22. The SYROCOT (Systematic Review on Congenital Toxoplasmosis) study group, Thiebaut R, Leproust S, Chene G, Gilbert R. Effectiveness of prenatal treatment for congenital toxoplasmosis: a meta-analysis of individual patients' data. Lancet. 2007;369:115-22.

23. Sauer A, de la Torre A, Gomez-Marin J, Bourcier T, Garweg J, Speeg-Schatz C, et al. Prevention of retinochoroiditis in congenital toxoplasmosis: Europe versus South America. Pediatr Infect Dis J. 2011;30:601-3.

24. Kotresha D, Noordin R. Recombinant proteins in the diagnosis of toxoplasmosis. APMIS. 2010;118:529-42.

25. Chaudhry SA, Gad N, Koren G. Toxoplasmosis and pregnancy. Can Fam Physician. 2014;60:334-6.

26. Gashout A, Amro A, Erhuma M, Al-Dwibe H, Elmaihub E, Babba H, et al. Molecular diagnosis of Toxoplasma gondii infection in Libya. BMC Infect Dis. 2016;16:157.

27. Khan K, Khan W. Congenital toxoplasmosis: an overview of the neurological and ocular manifestations. Parasitol Int. 2018;67:715-21.

28. Khanaliha K, Motazedian MH, Kazemi B, Shahriari B, Bandehpour M, Sharifniya Z. Evaluation of recombinant SAG1, SAG2, and SAG3 antigens for serodiagnosis of toxoplasmosis. Korean J Parasitol. 2014;52:137-42.

29. Sonaimuthu P, Fong MY, Kalyanasundaram R, Mahmud R, Lau YL. Sero-diagnostic evaluation of Toxoplasma gondii recombinant Rhoptry antigen 8 expressed in E. coli. Parasit Vectors. 2014;7:297.

30. Deng H, Devleesschauwer B, Liu M, Li J, Wu Y, van der Giessen JWB, et al Seroprevalence of Toxoplasma gondii in pregnant women and livestock in the mainland of China: a systematic review and hierarchical metaanalysis. Sci Rep. 2018;8:6218.

31. Furtado JM, Winthrop KL, Butler NJ, Smith JR. Ocular toxoplasmosis I: parasitology, epidemiology and public health. Clin Exp Ophthalmol. 2013:41:82-94.
32. Pereira-Chioccola VL, Vidal JE, Su C. Toxoplasma gondii infection and cerebral toxoplasmosis in HIV-infected patients. Future Microbiol. 2009:4:1363-79.

33. The Joint United Nations Programme on HIV/AIDS - UNAIDS. The Gap report. Geneva: UNAIDS; 2014.

34. Dedicoat M, Livesley N. Management of toxoplasmic encephalitis in HIV-infected adults (with an emphasis on resource-poor settings). Cochrane Database Syst Rev. 2006:CD005420.

35. Nissapatorn V. Toxoplasmosis in HIV/AIDS: a living legacy. Southeast Asian J Trop Med Public Health. 2009;40:1158-78.

36. Hill DE, Dubey JP. Toxoplasma gondii. In: Ortega Y, Sterling C, editors. Foodborne parasites food microbiology and food safety. New York: Springer; 2018. p. 119-38.

37. Shimelis T, Tebeje M, Tadesse E, Tegbaru B, Terefe A. Sero-prevalence of latent Toxoplasma gondii infection among HIV-infected and HIV-uninfected people in Addis Ababa, Ethiopia: a comparative cross-sectional study. BMC Res Notes. 2009;2:213.

38. Walle F, Kebede N, Tsegaye A, Kassa T. Seroprevalence and risk factors for toxoplasmosis in HIV infected and non-infected individuals in Bahir Dar, Northwest Ethiopia. Parasit Vectors. 2013;6:15.

39. Lindstrom I, Kaddu-Mulindwa DH, Kironde F, Lindh J. Prevalence of latent and reactivated Toxoplasma gondii parasites in HIV-patients from Uganda. Acta Trop. 2006;100:218-22.

40. Bessong PO, Mathomu LM. Seroprevalence of HTLV1/2, HSV1/2 and Toxoplasma gondii among chronic HIV-1 infected individuals in rural northeastern South Africa. Afr J Microbiol Res. 2010;4:2587-91.

41. Hari KR, Modi MR, Mochan AH, Modi G. Reduced risk of Toxoplasma encephalitis in HIV-infected patients-a prospective study from Gauteng, South Africa. Int J STD AIDS. 2007;18:555-8.

42. Oshinaike OO, Okubadejo NU, Ojini FI, Danesi MA. A preliminary study of the frequency of focal neurological deficits in HIV/AIDS patients seropositive for Toxoplasma gondii lgG in Lagos, Nigeria. Nig Q J Hosp Med. 2010;20:104-7.

43. Wallon M, Peyron F. Congenital toxoplasmosis: a plea for a neglected disease. Pathogens. 2018;7:25

44. Alsammani MA. Sero-epidemiology and risk factors for Toxoplasma gondii among pregnant women in Arab and African countries. J Parasit Dis. 2016:40:569-79.

45. Capretti MG, De Angelis M, Tridapalli E, Orlandi A, Marangoni A, Moroni A, et al. Toxoplasmosis in pregnancy in an area with low seroprevalence: is prenatal screening still worthwhile? Pediatr Infect Dis J. 2014;33:5-10.

46. Zumla A, Savva D, Wheeler RB, Hira SK, Luo NP, Kaleebu P, et al. Toxoplasma serology in Zambian and Ugandan patients infected with the human immunodeficiency virus. Trans R Soc Trop Med Hyg. 1991;85:227-9.

47. Nabias R, Ngouamizokou A, Migot-Nabias F, Mbou-Moutsimbi RA Lansoud-Soukate J. Serological investigation of toxoplasmosis in patients of the M.I.P. center of Franceville (Gabon). Bull Soc Pathol Exot. 1998;91:318-20.

48. Frimpong C, Makasa M, Sitali L, Michelo C. Seroprevalence and determinants of toxoplasmosis in pregnant women attending antenatal clinic at the university teaching hospital, Lusaka, Zambia. BMC Infect Dis. 2017;17:10.

49. Gelaye W, Kebede T, Hailu A. High prevalence of anti-toxoplasma antibodies and absence of Toxoplasma gondii infection risk factors among pregnant women attending routine antenatal care in two Hospitals of Addis Ababa, Ethiopia. Int J Infect Dis. 2015;34:41-5.

50. Flegr J, Prandota J, Sovickova M, Israili ZH. Toxoplasmosis-a global threat. Correlation of latent toxoplasmosis with specific disease burden in a set of 88 countries. PLoS ONE. 2014;9:90203.

51. Oyeyemi OT, Oyeyemi IT, Adesina IA, Tiamiyu AM, Oluwafemi YD, Nwuba Rl, et al. Toxoplasmosis in pregnancy: a neglected bane but a serious threat in Nigeria. Parasitology. 2020;147:127-34.

52. Fenta DA. Seroprevalence of Toxoplasma gondii among pregnant women attending antenatal clinics at Hawassa University comprehensive specialized and Yirgalem General Hospitals, in Southern Ethiopia. BMC Infect Dis. 2019;19:1056.

53. Jones JL, Kruszon-Moran D, Wilson M, McQuillan G, Navin T, McAuley JB. Toxoplasma gondii infection in the United States: seroprevalence and risk factors. Am J Epidemiol. 2001;154:357-65. 
54. Al-Eryani SM, Al-Mekhlafi AM, Al-Shibani LA, Mahdy MM, Azazy AA. Toxoplasma gondii infection among pregnant women in Yemen: factors associated with high seroprevalence. J Infect Dev Ctries. 2016;10:667-72.

55. Mabeku LB, Tchakounte C, Bonsi S, Etoa FX. Prevalence of Toxoplasma gondii and associated risk factors among pregnant women attending hospital centers in Penka-Michel, Cameroon. J Sci Res Rep. 2018;21:1-11.

56. Paquet $\mathrm{C}$, Yudin $\mathrm{MH}$, Society of $\mathrm{O}$, Gynaecologists of $\mathrm{C}$. Toxoplasmosis in pregnancy: prevention, screening, and treatment. J Obstet Gynaecol Can. 2013;35:78-81.

57. Torrey EF, Yolken RH. Toxoplasma gondii and schizophrenia. Emerg Infect Dis. 2003:9:1375-80.

58. de Oliveira GR, Vidal MF. A normal motor development in congenital hydrocephalus after Cuevas Medek Exercises as early intervention: a case report. Clin Case Rep. 2020;8:1226-9.

59. Dewan MC, Rattani A, Mekary R, Glancz LJ, Yunusa I, Baticulon RE, et al. Global hydrocephalus epidemiology and incidence: systematic review and meta-analysis. J Neurosurg. 2018:1-15.

60. Alayande M, Awosan K, Awosan J. Occurrence of antibody to Toxoplasma infection among pregnant women with obstetric histories and at different trimesters in Sokoto, Northwest Nigeria. Am J Res Com. 2013;1:240-7.

61. Ballah F, Maikai B, Magaji A, Shuaibu A, El-Nafaty A, Sambo Y, et al. Seroprevalence and risk of Toxoplasma gondii infection among pregnant women at Federal Teaching Hospital Gombe, Nigeria. Asian J Med Health. 2017;3:1-5.

62. Deji-Agboola M, Busari OS, Osinupebi OA, Amoo AOJ. Seroprevalence of Toxoplasma gondii antibodies among pregnant women attending antenatal clinic of federal medical center, Lagos, Nigeria. Int J Biol Med Res. 2011;2:1135-9.

63. Torgerson PR, Mastroiacovo P. The global burden of congenital toxoplasmosis: a systematic review. Bull World Health Organ. 2013:91:501-8.

64. Rezende HHA, Storchilo HR, Lima JAS, Gomes ARJ, Gomes TC, Souza JY, et al. Nursing infant with acquired toxoplasmosis in the first months of life_-a case report. Rev Inst Med Trop Sao Paulo. 2017;59:e63.

65. Lahmar I, Lachkhem A, Babba O, Slama D, Trabelsi A, Passebosc-Faure K, et al. First isolation and molecular characterization of Toxoplasma gondii strains from human congenital toxoplasmosis cases in Monastir, Tunisia. Sci Rep. 2020;10:1963.

66. Montoya JG, Liesenfeld O. Toxoplasmosis. Lancet. 2004;363:1965-76.

67. Fuglewicz AJ, Piotrowski P, Stodolak A. Relationship between toxoplasmosis and schizophrenia: a review. Adv Clin Exp Med. 2017;26:1031-6.

68. Ngo HM, Zhou Y, Lorenzi H, Wang K, Kim TK, Zhou Y, et al. Toxoplasma modulates signature pathways of human epilepsy, neurodegeneration \& cancer. Sci Rep. 2017;7:11496.

69. Sweetland AC, Oquendo MA, Sidat M, Santos PF, Vermund SH, Duarte $\mathrm{CS}$, et al. Closing the mental health gap in low-income settings by building research capacity: perspectives from Mozambique. Ann Glob Health. 2014;80:126-33.

70. Holub D, Flegr J, Dragomirecka E, Rodriguez M, Preiss M, Novak T, et al. Differences in onset of disease and severity of psychopathology between toxoplasmosis-related and toxoplasmosis-unrelated schizophrenia. Acta Psychiatr Scand. 2013;127:227-38.

71. Ngoungou EB, Bhalla D, Nzoghe A, Darde ML, Preux PM. Toxoplasmosis and epilepsy-systematic review and meta analysis. PLoS Negl Trop Dis. 2015;9:e0003525.

72. Palmer BS. Meta-analysis of three case controlled studies and an ecological study into the link between cryptogenic epilepsy and chronic toxoplasmosis infection. Seizure. 2007;16:657-63.

73. Stommel EW, Seguin R, Thadani VM, Schwartzman JD, Gilbert K, Ryan $\mathrm{KA}$, et al. Cryptogenic epilepsy: an infectious etiology? Epilepsia. 2001:42:436-8.

74. Ngugi AK, Bottomley C, Kleinschmidt I, Wagner RG, Kakooza-Mwesige A, Ae-Ngibise K, et al. Prevalence of active convulsive epilepsy in sub-Saharan Africa and associated risk factors: cross-sectional and casecontrol studies. Lancet Neurol. 2013;12:253-63.

75. Kamuyu G, Bottomley C, Mageto J, Lowe B, Wilkins PP, Noh JC, et al. Exposure to multiple parasites is associated with the prevalence of active convulsive epilepsy in sub-Saharan Africa. PLoS Negl Trop Dis. 2014:8:e2908.
76. Samia P, Hassell J, Hudson JA, Murithi MK, Kariuki SM, Newton CR, et al. Epilepsy diagnosis and management of children in Kenya: review of current literature. Res Rep Trop Med. 2019;10:91-102.

77. Alvarado-Esquivel C, Rascon-Careaga A, Hernandez-Tinoco J, CorellaMadueno MA, Sanchez-Anquiano LF, Aldana-Madrid ML, et al. Seroprevalence and associated risk factors for Toxoplasma gondii infection in healthy blood donors: a cross-sectional study in Sonora, Mexico. Biomed Res Int. 2016;2016:9597276.

78. Halonen SK. Use of human neurons derived via cellular reprogramming methods to study host-parasite interactions of Toxoplasma gondii in neurons. Cells. 2017;6:32.

79. Mahami Oskouei M, Hamidi F, Talebi M, Farhoudi M, Taheraghdam AA, Kazemi T, et al. The correlation between Toxoplasma gondii infection and Parkinson's disease: a case-control study. J Parasit Dis. 2016;40:872-6.

80. Torres L, Robinson SA, Kim DG, Yan A, Cleland TA, Bynoe MS. Toxoplasma gondii alters NMDAR signaling and induces signs of Alzheimer's disease in wild-type, C57BL/6 mice. J Neuroinflamm. 2018;15:57.

81. Rashno MM, Fallahi S, Kheirandish F, Bagheri S, Kayedi MH, Birjandi M. Seroprevalence of Toxoplasma gondii infection in patients with Alzheimer's disease. Arch Clin Infect Dis. 2016;11:e60133.

82. Cluver L, Orkin M, Boyes ME, Sherr L. Child and adolescent suicide attempts, suicidal behavior, and adverse childhood experiences in South Africa: a prospective study. J Adolesc Health. 2015;57:52-9.

83. Wagenaar BH, Cumbe V, Raunig-Berho M, Rao D, Kohrt BA, Stergachis A, et al. Outpatient mental health services in Mozambique: use and treatments. Psychiatr Serv. 2016;67:588-90.

84. Soleymani E, Faizi F, Heidarimoghadam R, Davoodi L, Mohammadi Y. Association of T. gondii infection with suicide: a systematic review and meta-analysis. BMC Public Health. 2020;20:766.

85. Instituto Nacional de Estatística. https://www.ine.gov.mz. Accessed 15 July 2020.

86. United Nations Development Programme. Human development report. Beyond income, beyond averages, beyond today: inequalities in human development in the 21st century. New York: United Nations Development Programme; 2019. p. 2019.

87. Noormahomed EV, Mocumbi AO, Ismail M, Carrilho C, Patel S, Nguenha $A$, et al. The medical education partnership initiative effect on increasing health professions education and research capacity in Mozambique. Ann Glob Health. 2018;84:47-57.

88. Government of Mozambique. Poverty reduction action plan (PARP) 2011-2014. Maputo: Government of Mozambique; 2011.

89. Grau-Pujol B, Massangaie M, Cano J, Maroto C, Ndeve A, Saute F, et al. Frequency and distribution of neglected tropical diseases in Mozambique: a systematic review. Infect Dis Poverty. 2019;8:103.

90. Noormahomed EV, Mascaro-Lazcano C. Onchocerciasis in Mozambique: an unknown condition for health professionals. EC Microbiol. 2019;15:160-7.

91. World Atlas. Countries with the highest rates of HIV/AIDs. 2019. https:// www.worldatlas.com/articles/countries-with-the-highest-rates-of-hivaids.html. Accessed 14 July 2020.

92. World Bank. The World Bank annual report 2009: year in review, volume 1. World Bank. 2009. https://openknowledge.worldbank.org/handl e/10986/4354. Accessed 15 July 2020.

93. Centers for Disease Control and Prevention. Division of Global HIV \& TB (DGHT). 2017. https://www.cdc.gov/globalhealth/resources/repor ts/annual/2017/division-of-global-hiv-tb-dght.html. Accessed 15 July 2020.

94. Sacarlal J, Denning DW. Estimated burden of serious fungal infections in Mozambique. J Fungi. 2018:4:75.

95. WHO. Number of people (all ages) living with HIV_-estimates by country. 2019. Geneva: World Health Organization; 2019. https://apps.who. int/gho/data/view.main.22100?lang=en. Accessed 21 July 2020.

96. dos Santos PF, Wainberg ML, Caldas-de-Almeida JM, Saraceno B, Mari JJ. Overview of the mental health system in Mozambique: addressing the treatment gap with a task-shifting strategy in primary care. Int J Ment Health Syst. 2016;10:1

97. WHO. Suicide in the world: global health estimates. Geneva: World Health Organization; 2019. https://apps.who.int/iris/handle/10665 /326948. Accessed 15 July 2020 
98. Francisco V Silveira J, Zacarias A. Suicide in Mozambique: evidence from 10 years mortuary data from forensic services at Maputo Central Hospital, Maputo city. Injury Prev. 2012;18:A166.

99. WHO. Epilepsy. 2019. Geneva: World Health Organization; 2019. https:// www.who.int/news-room/fact-sheets/detail/epilepsy. Accessed 15 July 2020

100. Patel V, Simbine AP, Soares IC, Weiss HA, Wheeler E. Prevalence of severe mental and neurological disorders in Mozambique: a population-based survey. Lancet. 2007:370:1055-60.

101. Dos Santos PF, Cumbe V, Gouveia ML, de Fouchier C, Teuwen D, Dua T. Implementation of mhGAP in Mozambique: integrating epilepsy care into the primary health care system. Int J Ment Health Syst. 2019;13:36

102. Salvador SF, Henriques JC, Munguambe M, Vaz RM, Barros HP. Hydrocephalus in children less than 1 year of age in northern Mozambique. Surg Neurol Int. 2014;5:175.

103. International Agency for the Prevention of Blindness. The IAPB vision atlas. https://atlas.iapb.org/about-vision-atlas/. Accessed 15 July 2020
104. Markovitz AA Simanek AM, Yolken RH, Galea S, Koenen KC Chen S, et al. Toxoplasma gondii and anxiety disorders in a community-based sample. Brain Behav Immun. 2015:43:192-7.

105. Ordi J, Castillo P, Garcia-Basteiro AL, Moraleda C, Fernandes F, Quinto L, et al. Clinico-pathological discrepancies in the diagnosis of causes of death in adults in Mozambique: a retrospective observational study. PLOS ONE. 2019:14:e0220657.

106. Sitoe SP, Rafael B, Meireles LR, Andrade HF Jr, Thompson R. Preliminary report of HIV and Toxoplasma gondii occurrence in pregnant women from Mozambique. Rev Inst Med Trop Sao Paulo. 2010;52:291-5.

\section{Publisher's Note}

Springer Nature remains neutral with regard to jurisdictional claims in published maps and institutional affiliations.
Ready to submit your research? Choose BMC and benefit from:

- fast, convenient online submission

- thorough peer review by experienced researchers in your field

- rapid publication on acceptance

- support for research data, including large and complex data types

- gold Open Access which fosters wider collaboration and increased citations

- maximum visibility for your research: over 100M website views per year

At $\mathrm{BMC}$, research is always in progress.

Learn more biomedcentral.com/submissions 